\title{
Increasing Lecturer Job Satisfaction by Strengthening Organizational Climate, Transformational Leadership and Interpersonal Communication
}

\author{
Nurhadi*, Didik Notosudjono, M. Entang \\ Pakuan University Bogor, Indonesia
}

*Corresponding Author: Nurhadi, Pakuan University Bogor, Indonesia

\begin{abstract}
Job satisfaction of lecturers is one of the important factors in producing quality graduates who can support the success of national education goals. The existing phenomenon, lecturer job satisfaction shows a low level of satisfaction. The purpose of this research is to find efforts to increase job satisfaction of Islamic college lecturers in Depok City through the development of organizational climate, transformational leadership and interpersonal communication. These efforts are carried out through the identification of the strengths between these variables. This research is a combination study using a correlational approach and SITOREM Analysis. Correlational statistical methods are used to determine whether organizational climate variables, transformational leadership and interpersonal communication have a positive relationship with lecturer job satisfaction. Scientific Identification Theory to Conduct Operations Research in Educational Management (SITOREM) analysis is used to determine the order of priorities and recommendations for improvement of the indicators needed. The results of the study of 138 Islamic college lecturers in Depok City showed that all variables were positively related to lecturer job satisfaction. The results of the correlation strength sequence based on the highest correlation are organizational climate $r_{y 1}=0.442(p<0.01)$, transformational leadership $r_{y 2}=0.374(p<0.01)$ and interpersonal communication $r_{y 3}=0.214(p<0.01)$. SITOREM Analysis Results show that indicators that need improvement are policies and promotion opportunities. Policy indicators are part of the organizational climate variable, while promotion opportunity indicators are part of the job satisfaction variable. Policy indicators in the organization's climate are followed up with workshops.
\end{abstract}

Key words: Co rrelational, SITOREM Analysis, job satisfaction, organizational climate, transformational leadership, interpersonal communication.

\section{INTRODUCTION}

Education is one of the keys to the success of the Indonesian people to be able to compete, and side by side with other nations in the world, including higher education, carried out by universities. Only with education can we compete with developed countries, we see our neighboring countries, India, Pakistan and Bangladesh which have carved the names of their scientists in the world of science and technology. University graduates are expected to be able to actualize the nation's competitive ability in all aspects of human life (Fangidae, 2016).

Lecturer job satisfaction is an important factor in producing quality graduates. Lecturers are satisfied that their work will do their job well, the quality of education and learning provided by lecturers to their students will be of good quality so that the purpose of education to produce quality graduates is achieved. Conversely, if lecturer job satisfaction is low, lecturers will tend to work as they wish. As a result, the learning process will not go well. This will result in students not getting less optimal learning. As a result, further students will become graduates whose quality does not match the stated educational goals.

The existing phenomenon, lecturer job satisfaction shows a low level of satisfaction. Findings in the field through a preliminary survey in December 2018, of 30 city Islamic college lecturers in Depok; there are $47 \%$ of lecturers who are dissatisfied with salaries and wages received, there are $36 \%$ of lecturers who are dissatisfied with promotion opportunities, there are $30 \%$ of lecturers who are dissatisfied with relations with colleagues, $43 \%$ of lecturers are dissatisfied with supervision superiors, there are $38 \%$ of lecturers who are not satisfied with work. 
The data shows that the Islamic college lecturers' job satisfaction is still low, especially in Depok. If this condition is left, then it will have an impact on the performance of lecturers, so it is necessary to look for effective efforts to increase lecturer job satisfaction immediately. Therefore it is necessary to research job satisfaction of lecturers and the factors associated with it. This research will focus on the relationship of lecturer job satisfaction with organizational climate factors, transformational leadership and interpersonal communication so that recommendations are obtained for efforts to increase lecturer job satisfaction through these factors.

The problem formulation of this study is, "Can lecturers' job satisfaction be improved by strengthening organizational climate, transformational leadership and interpersonal communication?".

In detail, the problem is formulated as follows:

1. Is there a relationship between organizational climate and job satisfaction of lecturers?

2. Is there a relationship between transformational leadership and job satisfaction of lecturers?

3. Is there a relationship between interpersonal communication with job satisfaction of lecturers?

4. Is there a relationship between organizational climate, transformational leadership and interpersonal communication together with lecturer job satisfaction?

\section{LITERATURE REVIEW}

\subsection{Job Satisfaction}

Colquitt Doghnaze (2012) formulates job satisfaction as an emotional state of an individual arising from an assessment of his work, or experiences at work. There are 5 (five) factors that most individuals want to obtain or enjoy while working, namely: a. salary (high and certain), b. promotion (opportunity based on performance and ability), c. Boss supervision (a good working relationship with the boss, and the award), d. coworkers (good and responsible relationship), and e. the work itself (the freedom to realize abilities, creations, achievements, etc.).

Meanwhile, according to Theresia (2018), job satisfaction is a general attitude of an individual towards his job. There are 4 (four) factors that affect job satisfaction: a. challenging jobs, jobs that provide opportunities to use skills and abilities and provide a variety of tasks, freedom and feedback about how well they work, b. Appropriate rewards, employees want a fair payment system, unambiguous and in line with employee expectations, c. supportive working conditions, related to a comfortable work environment and ease of doing work (spatial planning, clean workspace, facilities and assistive devices, temperature and noise level), d. Supportive colleagues, such as mutual respect, loyalty and tolerance between one another, open attitude and intimacy between employees.

\subsection{Organizational Climate}

Meanwhile, according to Gibson (2010), organizational climate is a set of equipment from a work environment that is felt directly or indirectly by employees who work and assume will be the main force affecting their behaviour in work. Factors affecting organizational climate: a. size and structure, b. leadership patterns, c. system complexity, d. organizational goals, e. communication network.

According to Syauta (2018), organizational climate is a concept that describes the subjective nature or quality of the organization's environment. Classification of organizational climate dimensions is a. responsibility, b. flexibility, c. standard, c. team commitment, d. clarity, e. awards, f. leadership style.

According to Kirkman (2017), organizational climate is a concept that describes the internal atmosphere of the organizational environment felt by its members during their activities to achieve organizational goals. The factors are a. leadership quality, b. trust, c. communication, $d$. responsibility, f. fair rewards, g. chance, h. control.

Based on the above notions, it can be synthesized that the organizational climate is the employee's perception of the work environment that affects individual behaviour in the organization to achieve organizational goals. The indicators are a. structure, b. leadership, c. policy, d. responsibility, and e. the warmth of the relationship.

\subsection{Transformational Leadership}

According to Garcia (2012), transformational leadership is leadership that involves inspiring all members to commit to a common vision that gives meaning to the development of their potential and 
some issues from new perspectives. The dimensions of transformational leadership are: a. idealized influence/charisma, b. intellectual stimulation / intellectual stimulation, c. individualized consideration / individual attention, $d$. inspirational motivation / motivation that inspires.

According to Diaz (2011), transformational leadership is a leader who inspires his subordinates to remove his interests for the good of the organization and has a great influence on his subordinates. The dimensions of transformational leadership are: a. idealized influence, a leader who gives vision and mission, the pride of respect and trust, $b$. inspirational motivation, a leader who communicates expectations, uses symbols to focus efforts, states important goals in a simple way, c. intellectual stimulation, a leader who is able to show intelligence, rationality, and solve problems carefully, d. individual consideration, a leader who gives personal attention, treats his subordinates individually, guides and advises.

Based on the above notions, it can be synthesized that transformational leadership is the behaviour of leaders who involve employees to commit and influence their subordinates to move together to achieve organizational goals. The dimensions/indicators of transformational leadership are: a. idealized influenced, charismatic, being a vision model, b. inspirational motivation, creating clear symbols/images, moving hearts, creating a strategic vision, c. intellectual stimulation has high intelligence, rationality, consistent, d. individual consideration, great attention, empowering, serving, and developing.

\subsection{Interpersonal Communication}

According to Hargie (2010), interpersonal communication is a verbal exchange of thoughts or ideas with each other. Interpersonal communication can take place effectively if several aspects must be considered by the actors of interpersonal communication. These aspects are a. Open-minded (openness), b. Empathy (empathy), c. supportiveness, d. positive attitude (positiveness), e. equality (equality).

According to Braitwhite (2014), interpersonal communication is communication that flows between individuals face to face and in group situations. Dimensions or factors of interpersonal communication, according to Gibson (2010), are: a. openness, which is the willingness to respond with pleasure to information received, b. honesty, in this case, the nature of sincerity in communicating with other parties, c. good feedback is the recipient's response to the message delivered.

Based on the above meanings, it can be synthesized that interpersonal communication is an interpersonal interaction in exchanging messages and ideas that produce meaning to get mutual agreement. The indicators of interpersonal communication are: a. openness (assessing objectively, responding with enthusiasm, behaviour, b. empathy (understanding other people's positions, selfstatus, other people's images, not distinguishing), c. positive attitude (showing interest, expressive behaviour, closeness, fission, beliefs, attention), d. the similarity of meaning (atmosphere of similarity, unity of mind), e. feedback (receiving the response, enthusiasm, ongoing response, message delivery).

\section{METHODS}

This study included all Private Islamic Religious Colleges in Depok, West Java, totaling 7 (seven) tertiary institutions. The seven Islamic colleges are scattered in several areas of the city of Depok. Islamic College is under the coordination of the Ministry of Religion's Director General of High Directorate through the coordinator of private Islamic religious colleges

This study uses a combination of research methods (mixed methods). Mixed methods are research methods that combine two or more methods in the process of gathering and analyzing research. Research data collection is carried out by distributing questionnaires to respondents who have been selected as samples. The results of the questionnaire were collected and recorded to analyze the data to test the research hypotheses and to find out the strength of the relationship between organizational climate, transformational leadership and interpersonal communication with job satisfaction. The data analysis technique used in this study is descriptive and inferential data analysis techniques. Descriptive statistics, namely statistical science that can present data through the most important and relevant data collection and summary to be included in the data analysis tool. While inferential 
Increasing Lecturer Job Satisfaction by Strengthening Organizational Climate, Transformational Leadership and Interpersonal Communication

statistics, namely statistical science that acts as a data analysis tool that has been presented in descriptive statistics.

In this study, the Qualitative Recommendation analysis method is used to supplement the results of Quantitative Research. Implementation of Qualitative Research Methods Conducted using the SITOREM Method. SITOREM stands for "Scientific Identification Theory to Conduct Operations Research in Educational Management", which in general can be interpreted as a scientific method used to identify variables (theory) to carry out "Operational Research" in the field of Education Management(Hardhienata, 2007).

\section{RESUltS AND DisCUSSION}

\subsection{Relationship Between Organizational Climate and Job Satisfaction of Lecturers of Private Islamic Religious Colleges in Depok City}

Organizational Climate with Lecturer Job Satisfaction. Contribution of Organizational Climate is shown by the coefficient of determination $\left(\mathrm{r}_{\mathrm{y} 1}{ }^{2}\right)$ of 0.1954 which means that Organizational Climate contributes $19.54 \%$ to the Job Satisfaction of Lecturers. In comparison, the remaining $80.46 \%$ is determined by other variables.

The significant positive relationship between organizational climate and Job Satisfaction has also been proven by the results of previous studies such as those conducted by, among others, Bhuto (2012), which states that organizational climate is significantly related to job satisfaction with a correlation coefficient of 0.685 at a significance level of 0,01 which shows there is a significant positive relationship between Organizational Climate and Job Satisfaction.

In the description of the research data, the total score of the total indicators of the Organizational Climate variable, the value is 4.08 , which means it is included in the high category. Besides, from the results of frequency distribution data, there are around $30.43 \%$ of lecturers still have low job satisfaction. So, from this data, efforts still need to be increased by the Islamic college organization in Depok so that the lecturers truly feel the organizational climate that supports their work.

The results of the study show the correlation coefficient $\left(r_{y 1}\right)$ of 0.422 . This value is not much different from the relevant research results which show that the correlation coefficient between Organizational Climate and Lecturer Job Satisfaction is indeed not so high it is also seen in the contribution of Organizational Climate shown by the correlation coefficient $\left(\mathrm{r}_{\mathrm{y} 1}\right)$ of 0.1954 which means that Organizational Climate contributes only $19.54 \%$ to the Job Satisfaction of Islamic college Lecturers in Depok city. In comparison, the remaining $80.46 \%$ is determined by other variables.

This is reinforced by the results of qualitative research by analyzing interviews, observations, documents and FGDs at private Islamic college in Depok City, which indicate that the higher the organizational culture, the higher the lecturer job's satisfaction will be.Based on the description above, the organizational climate is one of the determining factors in increasing the job satisfaction of Islamic college lecturers in Depok.

\subsection{Relationship Between Transformational Leadership and Job Satisfaction of Lecturers of Private Islamic Religious Colleges in Depok City}

The correlation coefficient value $\left(\mathrm{r}_{\mathrm{y} 2}\right)$ of 0.3744 shows a positive relationship between Transformational Leadership and Job Satisfaction of Lecturers. The contribution of Transformational Leadership is shown by the coefficient of determination $\left(\mathrm{r}_{\mathrm{y} 2}{ }^{2}\right)$ of 0.1402 which means that Transformational Leadership contributes $14.02 \%$ to Lecturer Job Satisfaction. In comparison, the remaining $85.98 \%$ is determined by other variables.

The significant positive relationship between Transformational Leadership and Job Satisfaction has also been proven by the results of previous studies as conducted by Braun (2014), which shows that there is a significant relationship between transformational leadership styles on job satisfaction of nurses in private hospitals in Jordan. Correlation coefficient 0.392 with note $\mathrm{p} 01$, thus the results obtained that transformational leadership is related to job satisfaction.

In the description of the research data, the average total score of the Transformational Leadership variable indicators, the value is 4.23 , which means that it is included in the high category. Besides, from the results of frequency distribution data, there are around $30.43 \%$ of lecturers still have low job satisfaction. So, from this data, efforts still need to be increased by the Islamic College organization in 
Increasing Lecturer Job Satisfaction by Strengthening Organizational Climate, Transformational Leadership and Interpersonal Communication

Depok so that its lecturers feel the influence of transformational leadership in their respective Islamic College.

The results showed the value of the correlation coefficient $\left(\mathrm{r}_{\mathrm{y} 2}\right)$ of 0.374 . This value is not much different from the relevant research results which show that the correlation coefficient between Transformational Leadership and Lecturer Job Satisfaction is not so high, it can also be seen in the contribution of Transformational Leadership shown by the correlation coefficient $\left(\mathrm{r}_{\mathrm{y} 2}\right)$ of 0.1402 which means that Transformational Leadership contributed only $14.02 \%$ to the Job Satisfaction of Islamic College Lecturers in the city of Depok, while the remaining $85.98 \%$ was determined by other variables (Rajiani,2010).

This is reinforced by the results of qualitative research by analyzing interviews, observations, documents and FGDs at private Islamic college in Depok City, which indicate that the higher the transformational leadership, the higher the lecturer job's satisfaction will be.Based on the description above, transformational leadership is one of the determining factors in increasing the job satisfaction of Islamic College lecturers in Depok.

\subsection{Relationship Between Interpersonal Communication and Job Satisfaction of Lecturers of Private Islamic Religious Colleges in Depok City}

The correlation coefficient value $\left(r_{\mathrm{y} 3}\right)$ of 0.2148 shows a positive relationship between Interpersonal Communication and Job Satisfaction of Lecturers. The contribution of Interpersonal Communication is shown by the coefficient of determination $\left(\mathrm{r}_{\mathrm{y} 3}{ }^{2}\right)$ of 0.0461 which means that Interpersonal Communication contributes $4.61 \%$ to the Job Satisfaction of Lecturers, while the remaining $95.39 \%$ is determined by other variables.

The significant positive relationship between Interpersonal Communication and Job Satisfaction has also been proven by the results of previous studies such as that of Fussel (2014), using quantitative and qualitative methods, the results showed that there was a positive relationship between interpersonal communication and teacher job satisfaction with a correlation coefficient of 0.942 , the results are obtained that transformational leadership is related to job satisfaction.

In the description of the research data, the total score of the total indicators of Interpersonal Communication variables is 4.28 , which means it is included in the high category. Besides, from the results of frequency distribution data, there are around $30.43 \%$ of lecturers still have low job satisfaction. So, from this data, efforts still need to be increased by the Islamic College organization in Depok so that its lecturers feel interpersonal communication that supports the environment in their respective Islamic College.

The results showed the correlation coefficient $\left(\mathrm{r}_{\mathrm{y} 2}\right)$ of 0.215 . This value is far different from the relevant research results, which show that the correlation coefficient between Interpersonal Communication and Lecturer Job Satisfaction is not too high. This can also be seen in the contribution of Interpersonal Communication shown by the correlation coefficient $\left(r_{\mathrm{y} 2}\right)$ of 0.0461 , which means that Interpersonal Communication contributes only $4.61 \%$ to the Job Satisfaction of Islamic College Lecturers in Depok, while the remaining 95.39\% determined by other variables.

This is reinforced by the results of qualitative research by analyzing interviews, observations, documents and FGDs at private Islamic college in Depok City, which indicate that the higher the interpersonal communication, the higher the lecturer job's satisfaction will be. Based on the description above, interpersonal communication is one of the determining factors in increasing the job satisfaction of Islamic College lecturers in Depok.

\subsection{Relationship Between Organizational Climate, Transformational Leadership and Interpersonal Communication Together with Job Satisfaction of Lecturers of Private Islamic Religious Colleges in Depok City}

The relationship model between Organizational Climate, Transformational Leadership and Interpersonal Communication together with Lecturer Job Satisfaction can be expressed in the multiple linear regression equation $\hat{Y}=75.007+0.338 \mathrm{X}_{1}+0.195 \mathrm{X}_{2}+0.003 \mathrm{X}_{3}$ which means that if the value of Organizational Climate, Transformational Leadership and the value of Interpersonal Communication increases by one unit, it will be followed by an increase in Lecturer Job Satisfaction value of $0.338,0195$ and 0.003 units with a constant of 75.007. Equation regression $\hat{Y}=75.007+$ 
$0,338 \mathrm{X}_{1}+0,195 \mathrm{X}_{2}+0,003 \mathrm{X} 3$ can be used to predict job satisfaction score if the score Organizational Climate Lecturer, Transformational Leadership and Interpersonal Communication known.

The value of the multiple correlation coefficient $\left(r_{\mathrm{y} 123}\right)$ of 0.4720 shows a positive relationship between Organizational Climate, Transformational Leadership and Interpersonal Communication, together with lecturer job satisfaction. The contribution of Transformational Leadership and Interpersonal Communication together, indicated by the coefficient of determination $\left(\mathrm{r}_{\mathrm{y} 123^{2}}{ }^{2}\right.$ of 0.2230 which means that Organizational Climate, Transformational Leadership and Interpersonal Communication together contribute $22.30 \%$ to Satisfaction Lecturer work, while the remaining $78.70 \%$ is determined by other variables.

Job satisfaction is employees' perceptions, attitudes and recognition of what they feel happy or unhappy about some aspects of their work. Organizational climate is the employee's perception of the work environment that influences the behaviour of individuals in the organization to achieve organizational goals. Interpersonal communication is interpersonal interaction in exchanging messages or ideas that produce meaning to get mutual agreement. Transformational leadership is the behaviour of leaders who involve employees to commit and influence subordinates to move together to achieve organizational goals (Rajiani, 2011).

The organizational climate tends to contribute to the achievement of shared goals in a way beyond. Transformational leadership motivates followers to internalize and prioritize collective interests that are greater than individual interests to achieve goals. Interpersonal communication encourages individuals to behave, which creates excitement in working and carrying out their duties. Fulfilling a conducive work atmosphere in a healthy organizational climate, effective transformational leadership, interpersonal communication will be built and able to create job satisfaction, so that organizational goals will be achieved.

The value of the multiple correlation coefficient $\left(\mathrm{r}_{\mathrm{y} 123}\right)$ of 0.472 shows that a positive relationship between Organizational Climate, Transformational Leadership and Interpersonal Communication, together with Lecturer Job Satisfaction includes a moderate relationship. While the contribution of Organizational Climate, Transformational Leadership and Interpersonal Communication together towards Lecturer Job Satisfaction, shown by the coefficient of determination of $22.30 \%$ is also still relatively small, thus, efforts should be made to improve the Organizational Climate, Transformational Leadership together with Interpersonal communication in the Islamic College environment in Depok.

\subsection{Sitorem Analysis}

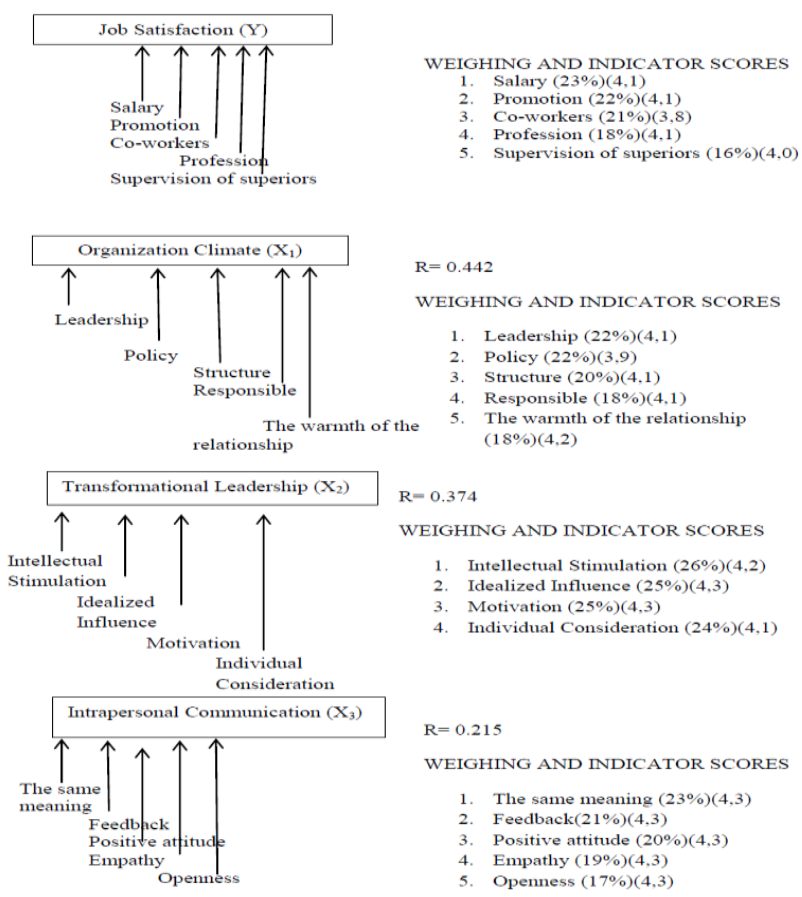

Figure1. Analysis of SITOREM (Scientific Identification Theory for Operational Research in Education 


\section{CONCLUSION}

This study was conducted with the aim of finding efforts to improve lecturer job satisfaction through the development of Organizational Climate, Transformational Leadership and Interpersonal Communication with Job Satisfaction of Islamic College Lecturers in Depok City. The effort was made by identifying the strengths of the relationship between these variables. Based on the results of the analysis, discussion of research results and hypotheses that have been tested, it can be concluded as follows:

Based on data analysis, the results of the study concluded that:

1. There is a positive relationship between the organization climate and lecturer job's satisfaction, with a correlation coefficient of 0.1954 or $19.54 \%$. The results of qualitative research show the same thing. This shows that the higher the organization climate, will higher the lecturer job's satisfaction and vice versa.

2. There is a positive relationship between the transformational leadership and lecturer job's satisfaction, with a correlation coefficient of 0.1452 or $14.52 \%$. The results of qualitative research show the same thing. This shows that the higher the transformational leadership, will thelecturer job's satisfaction and vice versa.

3. There is a positive relationship between interpersonal communication and lecturer job's satisfaction, with a correlation coefficient of 0.0461 or $4.61 \%$. The results of qualitative research show the same thing. This shows that the higher the interpersonal communication, will higher lecturer job's satisfaction and vice versa.

4. There is a positive relationship between the organizational climate, transformational leadership and interpersonal communication together with private Islamic college lecturer job satisfaction with a correlation coefficient of 0.472 . This indicates that lecturer job satisfaction can be improved through strengthening the organization climate, transformational leadership and interpersonal communication

\section{BIBLIOGRAPHY}

[1] Bhutto, N. A., \&Laghari, M. K. (2012). A comparative study of organizational climate and job satisfaction in public, private and foreign banks. Asian Social Science, 8(4), 259.

[2] Braithwaite, D. O., \&Schrodt, P. (Eds.). (2014). Engaging theories in interpersonal communication: Multiple perspectives. Sage Publications.

[3] Braun, S., Peus, C., Weisweiler, S., \& Frey, D. (2013). Transformational leadership, job satisfaction, and team performance: A multilevel mediation model of trust. The Leadership Quarterly, 24(1), 270-283.

[4] Diaz-Saenz, H. R. (2011). Transformational leadership. The SAGE handbook of leadership, 5(1), 299-310.

[5] Doghonadze, N. (2012). A survey on university lecturer job satisfaction. Journal of Education, 1(1), 17-22.

[6] Fanggidae, R. E., Suryana, Y., \&Efendi, N. (2016). Effect of a Spirituality Workplace on Organizational Commitment and Job Satisfaction (Study on the Lecturer of Private Universities in the Kupang CityIndonesia). Procedia-Social and Behavioral Sciences, 219, 639-646.

[7] Fussell, S. R., \&Kreuz, R. J. (Eds.). (2014). Social and cognitive approaches to interpersonal communication. PsychologyPress.

[8] García-Morales, V. J., Jiménez-Barrionuevo, M. M., \& Gutiérrez-Gutiérrez, L. (2012). Transformational leadership influence on organizational performance through organizational learning and innovation. Journal of business research, 65(7), 1040-1050.

[9] Gibson, D. E., \&Callister, R. R. (2010). Anger in organizations: Review and integration. Journal of Management, 36(1), 66-93.

[10] Hardhienata, S., 2017.The development of scientific identification theory to conduct operation research in education management. In IOP Conference Series: Materials Science and Engineering (Vol. 166, No. 1, p. 012007). IOP Publishing.

[11] Hargie, O. (2010). Skilled interpersonal communication: Research, theory and practice. Routledge.

[12] Kirkman, B. L., Lowe, K. B., \& Gibson, C. B. (2017). A retrospective on Culture's Consequences: The 35year journey. Journal of International Business Studies, 48(1), 12-29.

[13] Rajiani, I., \&Jumbri, I. A. (2011). The cultural ecology of new public management in Indonesia. Journal of Administrative Science, 8(1), 17-31. 
Increasing Lecturer Job Satisfaction by Strengthening Organizational Climate, Transformational Leadership and Interpersonal Communication

[14] Rajiani, I. (2010). Applying Personality Traits to Predict Loyalty and Neglect among Employees of Bank Jatim Located in 10 Big Cities of East Java (McCrae's and Hofstede's Theories on the effect of Culture on Personality Revisited). JurnalAplikasiManajemen, 8(3), 617-622.

[15] Syauta, J. H., Troena, E. A., \&MargonoSetiawan, S. (2012). The influence of organizational culture, organizational commitment to job satisfaction and employee performance (study at municipal waterworks of Jayapura, Papua Indonesia). International Journal of Business and Management Invention, 1(1), 69-76.

[16] Theresia, L., Lahuddin, A. H., Ranti, G., \&Bangun, R. (2018). The influence of culture, job satisfaction and motivation on the performance lecturer/employees. In International Conference on Industrial Engineering and Operations Management. Bandung (pp. 2541-2552).

Citation: Nurhadi, et.al. "Increasing Lecturer Job Satisfaction by Strengthening Organizational Climate, Transformational Leadership and Interpersonal Communication" International Journal of Managerial Studies and Research (IJMSR), vol 8, no. 7, 2020, pp. 72-79. doi: http:// dx.doi.org/10.20431/2349-0349.0807009.

Copyright: (C) 2020 Authors. This is an open-access article distributed under the terms of the Creative Commons Attribution License, which permits unrestricted use, distribution, and reproduction in any medium, provided the original author and source are credited. 